\title{
An inconvenient "truth" about using sensible heat flux as a surface boundary condition in models under stably stratifeid regimes
}

\section{Citation for published version (APA):}

Basu, S., Holtslag, A. A. M., Wiel, van de, B. J. H., Moene, A. F., \& Steeneveld, G. J. (2008). An inconvenient "truth" about using sensible heat flux as a surface boundary condition in models under stably stratifeid regimes. Acta Geophysica, 56(1), 88-99. https://doi.org/10.2478/s11600-007-0038-y

DOI:

10.2478/s11600-007-0038-y

Document status and date:

Published: 01/01/2008

Document Version:

Publisher's PDF, also known as Version of Record (includes final page, issue and volume numbers)

\section{Please check the document version of this publication:}

- A submitted manuscript is the version of the article upon submission and before peer-review. There can be important differences between the submitted version and the official published version of record. People interested in the research are advised to contact the author for the final version of the publication, or visit the DOI to the publisher's website.

- The final author version and the galley proof are versions of the publication after peer review.

- The final published version features the final layout of the paper including the volume, issue and page numbers.

Link to publication

\footnotetext{
General rights

- You may freely distribute the URL identifying the publication in the public portal. follow below link for the End User Agreement:

www.tue.nl/taverne

\section{Take down policy}

If you believe that this document breaches copyright please contact us at:

openaccess@tue.nl

providing details and we will investigate your claim.
}

Copyright and moral rights for the publications made accessible in the public portal are retained by the authors and/or other copyright owners and it is a condition of accessing publications that users recognise and abide by the legal requirements associated with these rights.

- Users may download and print one copy of any publication from the public portal for the purpose of private study or research.

- You may not further distribute the material or use it for any profit-making activity or commercial gain

If the publication is distributed under the terms of Article $25 \mathrm{fa}$ of the Dutch Copyright Act, indicated by the "Taverne" license above, please 


\title{
An inconvenient "truth" about using sensible heat flux as a surface boundary condition in models under stably stratified regimes
}

\author{
Sukanta BASU ${ }^{1}$, Albert A.M. HOLTSLAG ${ }^{2}$, Bas J.H. VAN DE WIEL ${ }^{2}$, \\ Arnold F. MOENE ${ }^{2}$, and Gert-Jan STEENEVELD ${ }^{2}$ \\ ${ }^{1}$ Atmospheric Science Group, Department of Geosciences, Texas Tech University \\ Lubbock, Texas, USA; e-mail: sukanta.basu@ttu.edu \\ ${ }^{2}$ Department of Meteorology and Air Quality, Wageningen University \\ Wageningen, The Netherlands
}

\begin{abstract}
In single column and large-eddy simulation studies of the atmospheric boundary layer, surface sensible heat flux is often used as a boundary condition. In this paper, we delineate the fundamental shortcomings of such a boundary condition in the context of stable boundary layer modelling and simulation. Using an analytical approach, we are able to show that for reliable model results of the stable boundary layer accurate surface temperature prescription or prediction is needed. As such, the use of surface heat flux as a boundary condition should be avoided in stable conditions.
\end{abstract}

Key words: boundary condition, land-atmosphere interaction, large-eddy simulation, PBL modelling, stable boundary layer

\section{GLOSSARY OF SYMBOLS}

$g \quad$ gravitational acceleration

$L \quad$ the Obukhov length $\left(=-\Theta_{0} u_{*}^{3} / \kappa g\langle w \theta\rangle\right)$

$U \quad$ wind speed at height $z$

$u, v, w \quad$ velocity fluctuations (around the average) in $x, y$ and $z$ directions

$u_{*} \quad$ friction velocity $\left(=\sqrt[4]{\langle u w\rangle^{2}+\langle v w\rangle^{2}}\right)$

(c) 2008 Institute of Geophysics, Polish Academy of Sciences 


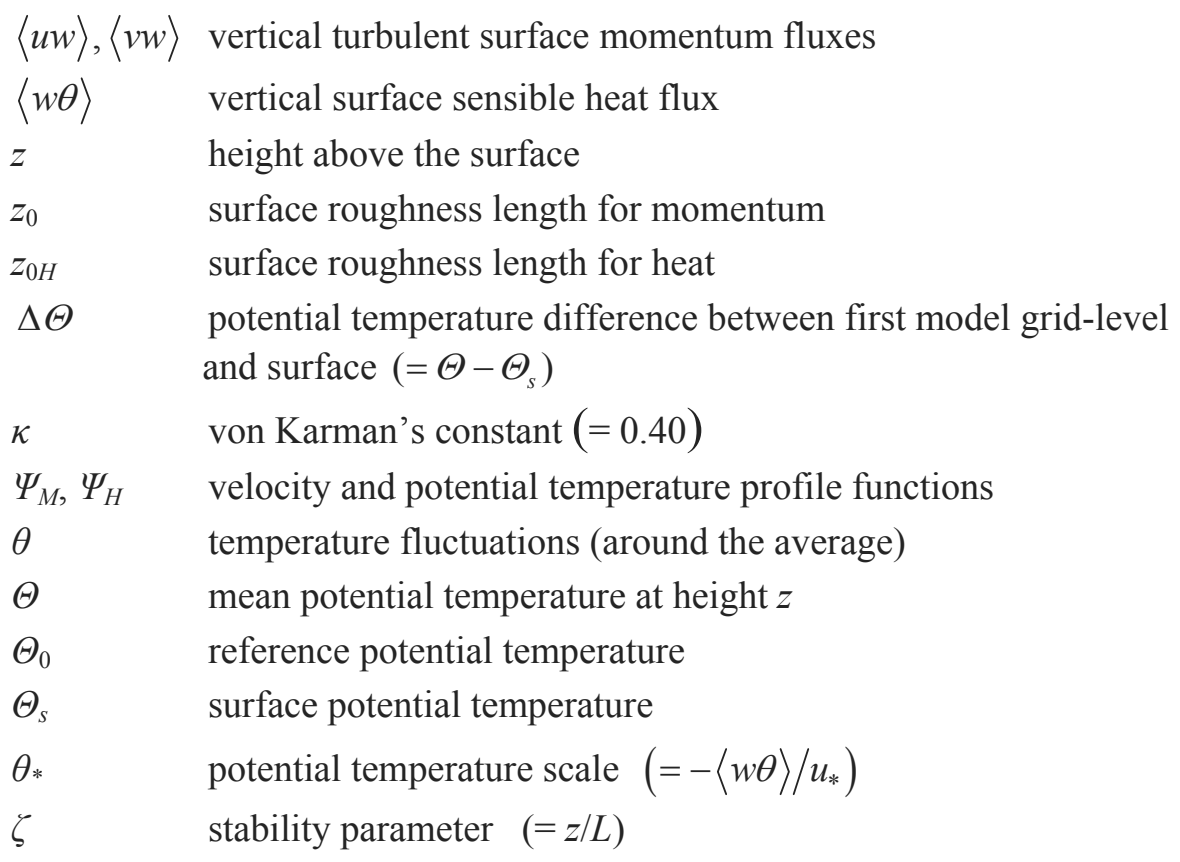

\section{INTRODUCTION}

Modelling of the stable boundary layer (SBL) over land is still a great challenge because of the occurrences of many complex physical processes, such as turbulence burstings, Kelvin-Helmholtz instabilities, gravity waves, low-level jets, meandering motions, et cetera (e.g., Hunt et al. 1996, Mahrt 1998, Derbyshire 1999, Holtslag 2006, Steeneveld et al. 2006). To enhance our understanding and to improve the representation of the boundary layer in atmospheric models for weather forecasting, climate modelling, air quality, and wind energy research, frequently model evaluation and intercomparison studies are organized (e.g., Lenderink et al. 2004, Cuxart et al. 2006, Beare et al. 2006, Svensson and Holtslag 2006, Steeneveld et al. 2007). Overall the aim of such studies is to identify the strengths and weaknesses of boundary layer turbulence parameterization schemes.

Usually evaluation studies are done with atmospheric column (1D) or large-eddy simulation (LES) models with simplified boundary conditions and forcing conditions, such as prescribing a constant geostrophic wind and a prescribed surface temperature (tendency). So far this has also been the approach within the GEWEX Atmospheric Boundary Layer Study (GABLS); see Cuxart et al. (2006) and Beare et al. (2006) for overviews of the 1D and LES model results for the first GABLS model intercomparison, respectively, and Svensson and Holtslag (2006) for the initial results of the second GABLS 1D model intercomparison.

Instead of prescribing surface temperature, one may also consider to prescribe surface sensible heat flux. This has been a useful approach for case studies over day- 
time conditions over land (e.g., Wyngaard and Coté 1974, Sun and Chang 1986, Nieuwstadt et al. 1993, Lenderink et al. 2004, Kumar et al. 2006). Due to the existence of 'dual' nature of sensible heat flux in stable conditions (see Malhi 1995, Mahrt 1998, Basu et al. 2006, Sorbjan 2006), application of sensible heat flux as a surface boundary condition is intuitively troublesome (elaborated later on). Notwithstanding, several SBL modelling studies opted for this type of boundary condition (e.g., Brown et al. 1994, Beljaars and Viterbo 1998, Saiki et al. 2000, Jiménez and Cuxart 2005, Kumar et al. 2006, Esau and Zilitinkevich 2006).

In this paper, we examine in depth the (negative) impact of using heat flux as a surface boundary condition in stable conditions. As such we use an analytical approach. It appears that Taylor (1971), DeBruin (1994), Malhi (1995) and Van de Wiel et al. (2007) provide useful corner steps on this issue as will be explained and summarized below. Section 2 gives background information on the subject as well as the implications for modelling when surface sensible heat flux is used as a boundary condition. In contrast, Section 3 gives the results when surface temperature is used as a boundary condition. Finally, Section 4 summarizes and concludes this paper.

\section{SENSIBLE HEAT FLUX-BASED SURFACE BOUNDARY CONDITION}

To illustrate the issue of this paper, it is useful to start with the wind velocity profile in the atmospheric surface layer. The wind velocity profile is typically written as (Stull 1988):

$$
U=\frac{u_{*}}{\kappa}\left[\ln \left(\frac{z}{z_{0}}\right)-\Psi_{M}\left(\frac{z}{L}\right)\right] .
$$

Using $\Psi_{M}(z / L)=-\alpha(z / L)$ for $z / L \geq 0$ (Businger et al. 1971, Dyer 1974) and utilizing the definition of the Obukhov length, we can re-write eq. (1a) as (Taylor 1971):

$$
U=\frac{u_{*}}{\kappa}\left[\ln \left(\frac{z}{z_{0}}\right)+\frac{\beta z}{u_{*}^{3}}\right],
$$

where $\beta=-\frac{\alpha \kappa g\langle w \theta\rangle}{\Theta_{0}}=\frac{\alpha u_{*}^{3}}{L}$. Rearranging eq. (1b), we arrive at a third-order polynomial in the friction velocity (Taylor 1971):

$$
u_{*}^{3}\left[\frac{1}{\kappa} \ln \left(\frac{z}{z_{0}}\right)\right]-u_{*}^{2} U+\frac{\beta z}{\kappa}=0 .
$$

Following van de Wiel et al. (2007), we divide eq. (2a) by $1 / \kappa \ln \left(z / z_{0}\right)$ and arrive at

$$
u_{*}^{3}-u_{*}^{2} \frac{U \kappa}{\ln \left(\frac{z}{z_{0}}\right)}+\frac{\beta z}{\ln \left(\frac{z}{z_{0}}\right)}=0 .
$$


Now, we define $u_{*_{N}}$ to be the friction velocity which would appear if no stability corrections were applied such as under neutral conditions (i.e., $z / L=0$ ). So by definition, $u_{*_{N}}=U \kappa / \ln \left(z / z_{0}\right)$, which can also be inferred from eq. (2b) for $\beta=0$. Such a definition has been found useful earlier in an analysis of the stable boundary layer (e.g., Holtslag and DeBruin 1988). Using $u_{*_{N}}$ in eq. (2b) and dividing eq. (2b) by $u_{*_{N}}^{3}$, we arrive at the following non-dimensional third-order polynomial:

$$
\left(\frac{u_{*}}{u_{*_{N}}}\right)^{3}-\left(\frac{u_{*}}{u_{*_{N}}}\right)^{2}+\frac{\beta z}{u_{*_{N}}^{3} \ln \left(\frac{z}{z_{0}}\right)}=0
$$

or

$$
\hat{u}_{*}^{3}-\hat{u}_{*}^{2}+\hat{H}=0,
$$

where

$$
\hat{u}_{*}=\frac{u_{*}}{u_{*_{N}}} \quad \text { and } \quad \hat{H}=\frac{\beta z}{u_{*_{N}}^{3} \ln \left(\frac{z}{z_{0}}\right)} .
$$

The equation as given by eq. (2d) has three roots (Taylor 1971). Let us first explore the results which appear when the surface heat flux has a maximum. As such, we need to impose $\mathrm{d} \hat{H} / \mathrm{d} \hat{u}_{*}=0$ and $\mathrm{d}^{2} \hat{H} / \mathrm{d} \hat{u}_{*}^{2}<0$. Differentiating eq. (2d), we get:

$$
\frac{\mathrm{d} \hat{H}}{\mathrm{~d} \hat{u}_{*}}=2 \hat{u}_{*}-3 \hat{u}_{*}^{2},
$$

and

$$
\frac{\mathrm{d}^{2} \hat{H}}{\mathrm{~d} \hat{u}_{*}^{2}}=2-6 \hat{u}_{*}
$$

Both the maximum criteria are satisfied for $\hat{u}_{*}=2 / 3$. Resubstitution of $\hat{u}_{*}=2 / 3$ in eq. (2d) leads to $\hat{H}_{\max }=4 / 27$. Using the definitions of $\hat{H}$ and $\beta$, we arrive at

$$
\langle w \theta\rangle_{\min }=-\frac{4}{27} \frac{\Theta_{0}}{\alpha \kappa g z} u_{*_{N}}^{3} \ln \left(\frac{z}{z_{0}}\right),
$$

or

$$
\langle w \theta\rangle_{\min }=-\frac{4}{27} \frac{\Theta_{0} \kappa^{2}}{\alpha g z} \frac{U^{3}}{\left[\ln \left(\frac{z}{z_{0}}\right)\right]^{2}} .
$$

This intriguing result for the minimum surface sensible heat flux, $\langle w \theta\rangle_{\min }$, was first derived by Malhi (1995), albeit following a slightly different derivation route. For the 
sake of brevity, in the rest of this paper, the condition $\langle w \theta\rangle=\langle w \theta\rangle_{\min }$ will be denoted as HMIN.

Taylor (1971) showed that eq. (2a) has two positive real roots if and only if

$$
(\kappa U)^{3}>\frac{27}{4} \beta z\left[\ln \left(\frac{z}{z_{0}}\right)\right]^{2} .
$$

This inequality leads with simple rearrangements to:

$$
\kappa^{2} U^{3}>\frac{27}{4} z\left(-\frac{\alpha g\langle w \theta\rangle}{\Theta_{0}}\right)\left[\ln \left(\frac{z}{z_{0}}\right)\right]^{2},
$$

or

$$
\langle w \theta\rangle>-\frac{4}{27} \frac{\Theta_{0} \kappa^{2}}{g z \alpha} \frac{U^{3}}{\left[\ln \left(\frac{z}{z_{0}}\right)\right]^{2}},
$$

or

$$
\langle w \theta\rangle>\langle w \theta\rangle_{\min }
$$

(recall that $\langle w \theta\rangle$ and $\langle w \theta\rangle_{\min }$ are both negative).

In other words, positive real roots of $u_{*}$ are guaranteed if and only if eq. (5d) is satisfied. Earlier, we showed that $\hat{u}_{* \text { HMIN }}$ is equal to $2 / 3$. Thus,

$$
u_{*_{H M I N}}=\frac{2}{3} u_{*_{N}}=\frac{2}{3} \frac{U \kappa}{\ln \left(\frac{z}{z_{0}}\right)} .
$$

This equation basically signifies that both the positive real roots of $u *$ become equal to $2 / 3 u_{*_{N}}$ at $H M I N$. This finding has recently been reported by van de Wiel et al. (2007).

Now, the value of the stability parameter, $\zeta$, at HMIN can be immediately found using the definitions of Obukhov length ( $L$, see Glossary of Symbols), $\langle w \theta\rangle_{\min }$ (i.e., eq. $4 \mathrm{~b}$ ), and $u_{*_{H M I N}}$ (i.e., eq. 6) as (see also Malhi 1995):

$$
\varsigma_{\text {HMIN }}=\left(\frac{z}{L}\right)_{\text {HMIN }}=\frac{\ln \left(z / z_{0}\right)}{2 \alpha} .
$$

In Fig. 1, we provide an example of the complex $u_{*}-\langle w \theta\rangle$ relationship. We assume: $U=5 \mathrm{~m} \mathrm{~s}^{-1}, z=10 \mathrm{~m}, z_{0}=0.1 \mathrm{~m}, \Theta_{0}=300 \mathrm{~K}, \alpha=5$, and $g=9.81 \mathrm{~m} \mathrm{~s}^{-2}$. We vary $\langle w \theta\rangle$ from 0 to $\langle w \theta\rangle_{\min } \mathrm{Km} \mathrm{s}^{-1}$. From eq. (4b), for this example we get: $\langle w \theta\rangle_{\min }=-0.0855 \mathrm{~K} \mathrm{~m} \mathrm{~s}^{-1}$ (see the dashed vertical lines in Fig. 1). In the left subplot, the positive real roots of eq. (2a) are shown. Following Taylor's convention (Taylor 

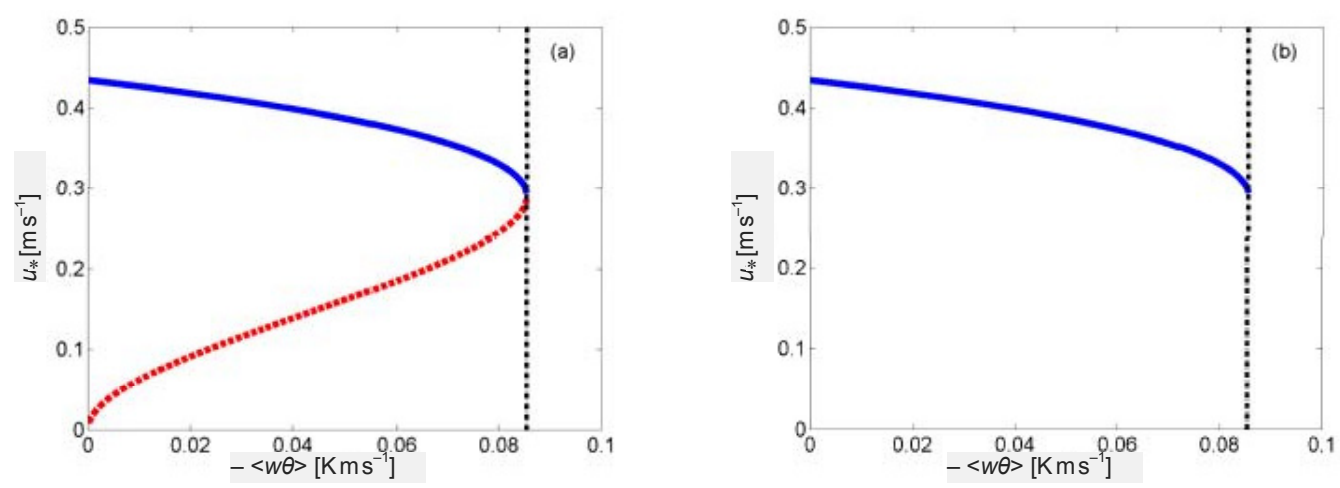

Fig. 1. Friction velocity as a function of prescribed heat flux. The dashed vertical lines denote the maximum achievable heat flux (refer to eq. $4 \mathrm{~b}$ ). The solid and dashed curves in the left subplot show the stable $\left(u_{*}^{+}\right)$and unstable $\left(u_{*}^{-}\right)$roots of the eq. $(2 \mathrm{a})$, respectively. The right subplot portrays the iterative solution for $u_{*}-$ see Algorithm 1 for details.

1971), the larger root is indicated as $u_{*}^{+}$, whereas, the smaller root by $u_{*}^{-}$. Taylor (1971) conjectured that $u_{*}^{+}$and $u_{*}^{-}$are (hydrodynamically) stable and unstable, respectively. A formal proof (based on linear stability analysis) has recently been given by van de Wiel et al. (2007).

In planetary boundary layer (PBL) models (single column or LES), $u_{*}$ is traditionally estimated iteratively by utilizing eq. (1a), rather than by solving the thirdorder polynomial (eq. 2a). A typical pseudocode is provided in Algorithm 1. Figure 1right portrays the iterative solution for $u_{*}$. Based on Fig. 1, we can conclude that:

- if the magnitude of the prescribed negative heat flux is less than or equal to $\langle w \theta\rangle_{\min }$, the iterative solution always leads to the stable root (i.e., $u_{*}^{+}$);

ALGORITHM 1: SURFFLUX1 $\left(U,\langle w \theta\rangle, z, z_{0}\right)$

Comment: Given $U,\langle w \theta\rangle, z$, and $z_{0}$, compute $u_{*}$.

Comment: $g, \alpha, \kappa$, and $\Theta_{0}$ are constants.

Initial value $\psi_{M} \leftarrow 0$

for iteration $\leftarrow 1$ to iteration $_{\max }$

$$
\text { do }\left\{\begin{array}{l}
u_{*} \leftarrow \frac{U \kappa}{\ln \left(z / z_{0}\right)-\psi_{M}} \\
L \leftarrow-\frac{\Theta_{0} u_{*}^{3}}{\kappa g\langle w \theta\rangle} \\
\psi_{M} \leftarrow-\frac{\alpha z}{L}
\end{array}\right.
$$


- if the magnitude of the prescribed negative heat flux is larger than $\langle w \theta\rangle_{\min }$, there is no real solution for $u *$;

- $u_{*}$ always resides in the range $\left[u_{*_{N}}, 2 / 3 u_{*_{N}}\right]$ for the corresponding prescribed heat flux range of $\left[0,\langle w \theta\rangle_{\min }\right]$. For the present example, $u_{*_{N}}=\left(u_{*}\right)_{\langle w \theta\rangle=0}=$ $0.434 \mathrm{~m} \mathrm{~s}^{-1}$. We numerically find that $u_{*}$ HMIN is $\sim 0.290 \mathrm{~m} \mathrm{~s}^{-1}-$ in close agreement with $2 / 3 u_{*_{N}}$.

\section{SURFACE TEMPERATURE-BASED SURFACE BOUNDARY CONDITION}

To explore the role of a surface temperature condition, it is useful to start with the profile equation for potential temperature. The latter can be written similar to eq. (1a), as in Stull (1988):

$$
-\Delta \Theta=\frac{\langle w \theta\rangle}{u_{*} \kappa}\left[\ln \left(\frac{z}{z_{0 H}}\right)-\Psi_{H}\left(\frac{z}{L}\right)\right] .
$$

Using $\Psi_{H}(z / L)=-\alpha(z / L)$ for $\quad z / L \geq 0 \quad$ (Arya 2001):

$$
-\Delta \Theta=\frac{\langle w \theta\rangle}{u_{*} K}\left[\ln \left(\frac{z}{z_{0 H}}\right)+\alpha\left(\frac{z}{L}\right)\right] .
$$

If surface potential temperature, $\Theta_{s}$, or the potential temperature difference between the first model grid-level and surface $\left(\Delta \Theta=\Theta-\Theta_{s}\right)$ is provided as a boundary condition, friction velocity and sensible heat flux can be estimated by solving the coupled eqs. (1b) and (8b). Analytical solutions of these coupled equations can be readily found if we further assume $z_{0}=z_{0 H}$. Bulk Richardson number, $R i_{B}$, for the atmospheric surface layer is typically written as

$$
R i_{B}=\frac{g z}{\Theta_{0}} \frac{\Delta \Theta}{U^{2}} .
$$

Using eqs. (1b) and ( $8 \mathrm{~b})$, we can re-write $R i_{B}$ as follows:

$$
R i_{B}=\frac{\frac{z}{L}}{\ln \left(\frac{z}{z_{0}}\right)+\alpha \frac{z}{L}} .
$$

Substituting $R i_{B}$ into eq. (1b), we get

$$
u_{*}=\frac{U \kappa}{\ln \left(\frac{z}{z_{0}}\right)}\left(1-\alpha R i_{B}\right) .
$$


Similarly, substituting $R i_{B}$ into eq. (8b) and using eq. (10a), we get

$$
\langle w \theta\rangle=-\frac{U \kappa^{2} \Delta \Theta}{\ln \left(\frac{z}{z_{0}}\right)^{2}}\left(1-\alpha R i_{B}\right)^{2} .
$$

Thus, in the case of $z_{0}=z_{0 H}$, given $U$ and $\Delta \Theta, u_{*}$ and $\langle w \theta\rangle$ could be easily estimated from eqs. (10a) and (10b) with the help of eq. (9a). For more general cases (e.g., $z_{0} \neq z_{0 H}$ ), the analytical solutions might become untractable. Then, Algorithm 2 or its variants could be effectively used for iterative solutions. Please note that eqs. (10a) and (10b) are valid for $R i_{B} \leq 1 / \alpha$. From eqs. (9a), (10a), and (10b), we also observe that $u_{*}$ and $\langle w \theta\rangle$ depend on $\Delta \Theta$ in linear and cubic fashions, respectively.

Now, we revisit the example problem discussed in the previous section. However, in this occasion instead of prescribing surface sensible heat flux, $\langle w \theta\rangle$, we vary the potential temperature difference between the first model grid-level and surface $(\Delta \Theta)$. All other variables remain the same. We further assume $z_{0}=z_{0 H}$ and $\Psi_{M}=\Psi_{H}=-\alpha z / L$.

The dual nature of surface sensible heat flux is clearly visible in Fig. 2a. The downward heat flux achieves its maximum possible value for a certain value of potential temperature difference between first model grid-level and surface, denoted as $\Delta \Theta_{\text {HMIN }}$ in this work. In the very stable regime $\left(\Delta \Theta » \Delta \Theta_{H M I N}\right)$ due to suppression of turbulence, the heat flux vanishes. Of course, the heat flux should also go to zero in the near-neutral limit $(\Delta \Theta \rightarrow 0)$ since the temperature fluctuations become quite

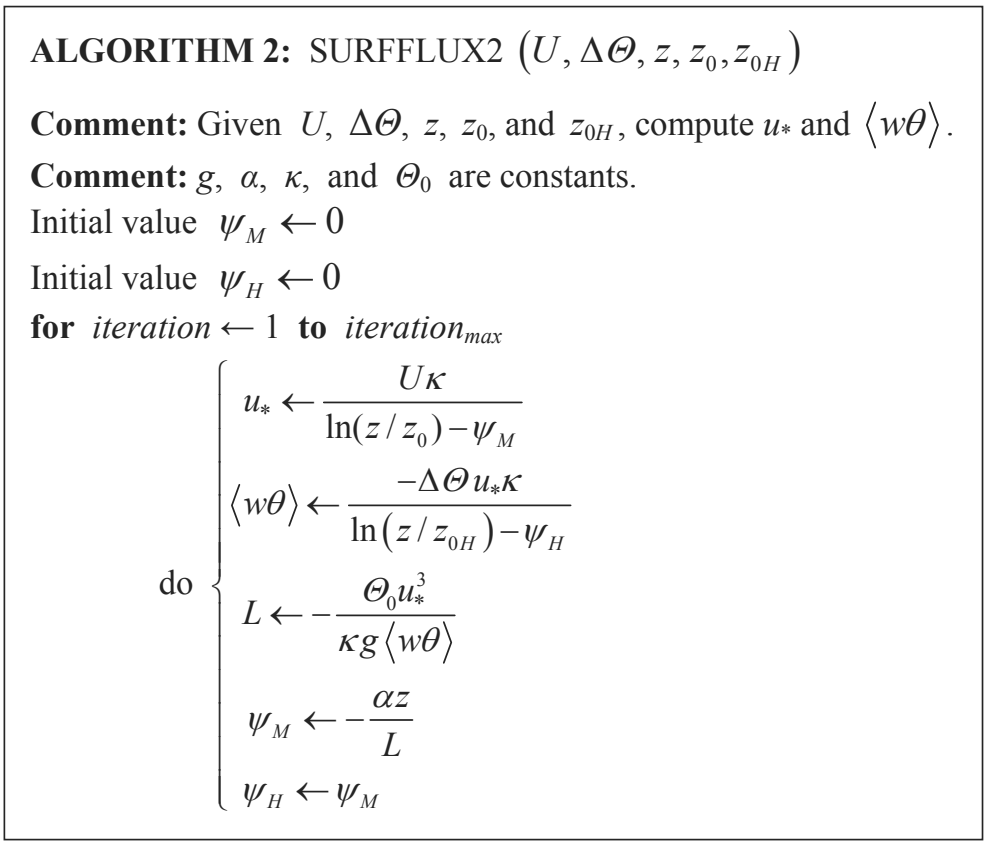



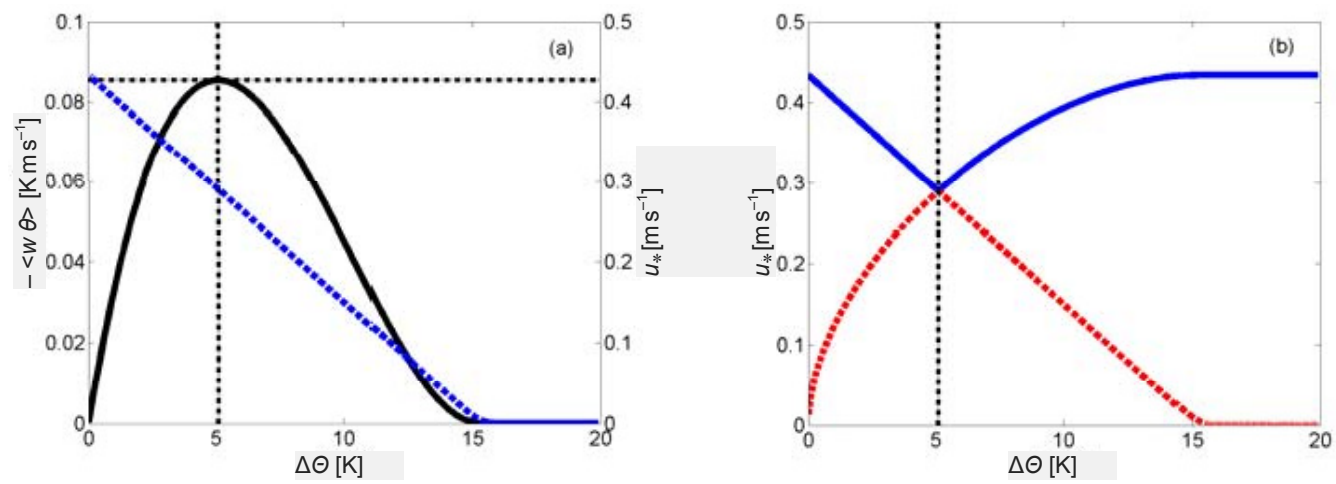

Fig. 2: (a) Sensible heat flux and friction velocity as functions of potential temperature difference between surface and first atmospheric model level. Algorithm 2 has been used to estimate these fluxes. The dashed horizontal line denotes the maximum achievable heat flux, refer to eq. (4b). The dashed vertical line indicates $\Delta \Theta_{H M I N}$, see eq. (11a), and related discussions; (b) The solid and dashed curves represent the stable $\left(u_{*}^{+}\right)$and unstable $\left(u_{*}^{-}\right)$roots of eq. (2a), respectively, given the estimated sensible heat flux of the left subplot as input. Similar to the left subplot, the dashed vertical line indicates $\Delta \Theta_{H M I N}$.

small. We would like to point out that Malhi (1995) reported qualitatively very similar stability parameter $(\zeta)$ versus heat flux curves. We would like to stress that the dual nature of sensible heat flux is not a numerical artifact, it has been reported in several recent observational studies. Malhi (1995) reported $\zeta_{\text {HMIN }}$ to be around 0.20. Based on the Microfonts data, Mahrt (1998) found $\zeta_{\text {HMIN }}$ to occur at 0.05. Basu et al. (2006) performed extensive analyses of turbulence data from several field campaigns and wind-tunnel experiments. They also provided convincing evidences of the duality of sensible heat flux. Based on CASES-99 observations and utilizing the 'gradient-based' local scaling hypothesis, Sorbjan (2006) found the normalized minimum surface sensible heat flux to be around $R i \approx 0.25$ (here $R i$ denotes the so-called gradient Richardson number).

Using eqs. (4b), (6), and (8b), along with the assumption of $z_{0}=z_{0 H}$, it is quite straightforward to show that

$$
\Delta \Theta_{H M I N}=\frac{U^{2} \Theta_{0}}{3 g z \alpha} .
$$

Thus, $\Delta \Theta_{\text {HмIN }}$ strongly depends on wind speed and height. Recent single column modelling study by Holtslag et al. (2007) also arrived at this conclusion numerically. Using the definition of $R i_{B}$, eq. (11a) can be re-arranged in the following dimensionless (quasi-universal) form:

$$
\left(R i_{B}\right)_{H M I N}=\frac{1}{3 \alpha} .
$$


For $\alpha=5$, eq. (11b) basically implies that minimum heat flux occurs at $R i_{B}=1 / 15$. In our future works, we will attempt to validate this interesting finding via extensive analyses of field observations.

Figure 2a portrays that the friction velocity (estimated using Algorithm 2) decreases monotonically with increasing surface inversion, as would be physically anticipated. Both $u_{*}$ and $\langle w \theta\rangle$ eventually go to zero (the so-called "collapse" phenomenon) for $\Delta \Theta>>\Delta \Theta_{\text {HMIN }}$. However, we earlier found that, if surface sensible heat flux is prescribed, the (hydrodynamically) stable root $u_{*}^{+}$only decreases upto $2 / 3 u_{*_{N}} \gg 0$ (see eq. (6) and Fig. 1). In order to resolve this anomaly, in Fig. 2-right, we have plotted both $u_{*}^{+}$and $u_{*}^{-}$using the iteratively estimated sensible heat flux of Fig. 2a and eq. (2a). Interestingly, for $\Delta \Theta \leq \Delta \Theta_{H M I N}$, the iteratively estimated $u_{*}$ (Fig. 2a) follows the stable root $u_{*}^{+}$(Fig. 2b, solid curve). But, for $\Delta \Theta>\Delta \Theta_{H M I N}$, the trend reverses, as it follows the unstable root $u_{*}^{-}$. We would like to emphasize that the stable root $u_{*}^{+}$increases with increasing stability for $\Delta \Theta>\Delta \Theta_{H M I N}$, which is physically unfeasible.

\section{SUMMARY AND CONCLUSION}

In this paper, we have discussed how the use of a prescribed sensible heat flux as a lower boundary condition will impact on the results of a PBL model. It is argued that any PBL model (single column or LES) will only be able to capture the near-neutral to weakly stable regime $\left(\Delta \Theta \leq \Delta \Theta_{\text {HMIN }}\right)$ if surface sensible heat flux is prescribed. As a result, the estimated $u_{*}$ will never become less than $67 \%$ of the neutral estimate for the friction velocity (e.g., $2 / 3 u_{*_{N}}$ in the case of the Businger-Dyer-type profiles). In order to represent the moderate to very stable regime $\left(\Delta \Theta>\Delta \Theta_{H M I N}\right.$ and $\left.u_{*}<2 / 3 u_{*_{N}}\right)$ in a boundary layer model for stably stratified conditions, unquestionably one needs to use surface temperature as a boundary condition as shown in this paper. In addition, model results also seem to depend on how the surface temperature condition is applied. Using a prescribed surface temperature or a surface temperature as predicted by a simple energy balance model, indicated strong impacts on the model results. This has been discussed by Holtslag et al. (2007).

Acknowledgements. This work was partially funded by the National Science Foundation (ANT-0538453) and the Texas Advanced Research Program (0036440003-2006) grants awarded to S. Basu. The Wageningen group acknowledges the Dutch Science Foundation NWO for sponsoring the project "Land Surface Climate and Role of the Stable Boundary Layer". Arnold Moene and Gert-Jan Steeneveld also acknowledge the Climate Changes Spatial Planning (BSIK) project. This paper was inspired by discussions at the June 2007 workshop on the GEWEX Atmospheric Boundary Layer Study (GABLS) as hosted by Gunilla Svensson of Stockholm University. 


\section{References}

Arya, S.P. (2001), Introduction to Micrometeorology, San Diego, Academic Press, 420 p.

Basu, S., F. Porté-Agel, E. Foufoula-Georgiou, J.-F. Vinuesa, and M. Pahlow (2006), Revisiting the local scaling hypothesis in stably stratified atmospheric boundary-layer turbulence: An integration of field and laboratory measurements with large-eddy simulations, Bound.-Layer Meteor. 119, 473-500.

Beare, R., M. MacVean, A.A.M. Holtslag, J. Cuxart, I. Esau, J.-C. Golaz, M. Jiménez, M. Khairoutdinov, B. Kosovic, D. Lewellen, T. Lund, J. Lundquist, A. McCabe, A. Moene, Y. Noh, S. Raasch, and P. Sullivan (2006), An intercomparison of largeeddy simulations of the stable boundary layer, Bound.-Layer Meteor. 118, 247-272.

Beljaars, A., and P. Viterbo (1998), The role of the boundary layer in a numerical weather prediction model. In: A.A.M. Holtslag and P.G. Duynkerke (eds.), Clear and Cloudy Boundary Layers, Amsterdam, Royal Netherlands Academy of Arts and Sciences, 297-304.

Brown, A.R., S.H. Derbyshire, and P.J. Mason (1994), Large-eddy simulation of stable atmospheric boundary layers with a revised stochastic subgrid model, Quart. J. Roy. Meteorol. Soc. 120, 1485-1512.

Businger, J.A., J.C. Wyngaard, Y. Izumi, and E.F. Bradley (1971), Flux-profile relationships in the atmospheric boundary layer, J. Atmos. Sci. 30, 788-794.

Cuxart, J., A.A. M. Holtslag, R.J. Beare, E. Bazile, A. Beljaars, A. Cheng, L. Conangla, M. Ek, F. Freedman, R. Hamdi, A. Kerstein, H. Kitagawa, G. Lenderink, D. Lewellen, J. Mailhot, T. Mauritsen, V. Perov, G. Schayes, G.J. Steeneveld, G. Svensson, P. Taylor, W. Weng, S. Wunsch, and K.-M. Xu (2006), Single-column model intercomparison for a stably stratified atmospheric boundary layer, Bound-Layer Meteor. 118, 273-303.

DeBruin, H.A.R. (1994), Analytic solutions of the equations governing the temperature fluctuation method, Bound.-Layer Meteor. 68, 427-432.

Derbyshire, S.H. (1999), Stable boundary-layer modelling: Established approaches and beyond, Bound.-Layer Meteor. 90, 423-446.

Dyer, A.J. (1974), A review of flux-profile relations, Bound.-Layer Meteor. 1, 363-372.

Esau, I.N., and S.S. Zilitinkevich (2006), Universal dependences between turbulent and mean flow parameters in stably and neutrally stratified planetary boundary layers, Nonlin. Processes Geophys. 13, 135-144.

Holtslag, A.A.M. (2006), GEWEX atmospheric boundary layer study (GABLS) on stable boundary layers, Bound.-Layer Meteor. 118, 243-246.

Holtslag A.A.M., and H.A.R. DeBruin (1988), Applied modeling of the nighttime surface energy balance over land, J. Appl. Meteorol. 27, 689-704.

Holtslag, A.A.M., G.J. Steeneveld, and B.J.H. Van de Wiel (2007), Role of land surface temperature feedback on model performance for stable boundary layers, Bound.-Layer Meteor. 125, 361-376, DOI: 10.1007/s10546-007-9214-5.

Hunt, J.C.R., G.J. Shutts and S. Derbyshire (1996), Stably stratified flows in meteorology, Dyn. Atmos. Oceans. 23, 63-79.

Jiménez, M.A., and J. Cuxart (2005), Large-eddy simulations of the stable boundary layer using the standard Kolmogorov theory: Range of applicability, Bound.-Layer Meteor. 115, 241-261. 
Kumar, V., J. Kleissl, C. Meneveau, and M.B. Parlange (2006), Large-eddy simulation of a diurnal cycle of the atmospheric boundary layer: atmospheric stability and scaling issues, Water Resour. Res. 42, W06D09, DOI:10.1029/2005WR004651.

Lenderink, G., A.P. Siebesma, S. Cheneit, S. Ihrons, C.G. Jones, P. Marquet, F. Muller, D. Olmera, J. Calvo, E. Sanchez, and P.M. M.Soares (2004), The diurnal cycle of shallow cumulus clouds over land: a single-column model intercomparison study, Quart. J. Roy. Meteor. Soc. 130, 3339-3364.

Mahrt, L. (1998), Stratified atmospheric boundary layers and breakdown of models, Theoret. Comput. Fluid Dyn. 11, 263-279.

Malhi, Y.S. (1995), The significance of the dual solutions for heat fluxes measured by the temperature fluctuations method in stable conditions, Bound.-Layer Meteor. 74, 389-396.

Nieuwstadt, F.T.M., P.J. Mason, C.-H. Moeng, and U. Schumann (1993), Large-eddy simulation of the convective boundary layer: a comparison of four computer codes. In: F. Durst, R. Friedrich, B.E. Launder, F.W. Schmidt, U. Schumann, and J.H. Whitelaw (eds.), Turbulent Shear Flows 8, Springer, Berlin, 343-367.

Saiki, E.M., C.-H. Moeng, and P.P. Sullivan (2000), Large-eddy simulation of the stably stratified planetary boundary layer, Bound.-Layer Meteor. 95, 1-30.

Sorbjan, Z. (2006), Local structure of turbulence in stably stratified boundary layers, J. Atmos. Sci. 63, 1526-1537.

Steeneveld, G.J., B.J.H. Van de Wiel, and A.A.M. Holtslag (2006), Modeling the evolution of the atmospheric boundary layer coupled to the land surface for three contrasting nights in CASES-99, J. Atmos. Sci. 63, 920-935.

Steeneveld, G.J., T. Mauritsen, E.I.F. de Bruijn, J. Vilà-Guerau de Arellano, G. Svensson, A.A.M. Holtslag (2007), Evaluation of limited area models for the representation of the diurnal cycle and contrasting nights in CASES99, J. Appl. Meteorol. Clim. (in press).

Stull, R.B. (1988), An Introduction to Boundary Layer Meteorology, Kluwer Academic Publishers, Dordrecht, $670 \mathrm{p}$.

Sun, W.-Y., and C.-Z. Chang (1986), Diffusion model for a convective layer. Part I: numerical simulation of convective boundary layer, J. Climate App. Meteorol. 25, 1445-1453.

Svensson, G., and A.A.M. Holtslag (2006), Single column modeling of the diurnal cycle based on CASES99 data - GABLS second intercomparison project. In: 17th Symposium on Boundary Layers and Turbulence, San Diego, USA, 22-25 May, American Meteorological Society, Boston, Paper 8.1. http://ams.confex.com/ams/pdfpapers/110758.pdf.

Taylor, P.A. (1971), A note on the log-linear velocity profile in stable conditions, Quart. J. Roy. Meteorol. Soc. 97, 326-329.

van de Wiel, B.J.H., A.F. Moene, G.J. Steeneveld, O.K. Hartogensis, and A.A.M. Holtslag (2007), Predicting the collapse of turbulence in stably stratified boundary layers, Turb. Flow Comb. 79, 251-274.

Wyngaard, J.C., and O.R. Coté (1974), The evolution of a convective planetary boundary layer - a higher-order-closure model study, Bound.-Layer Meteor. 7, 289-308. 